\title{
Organic Bio-Electronics: Bridging the Gap Between Natural and Artificial Materials for Bio-Electronics Applications
}

\author{
Godspower W. Omokhunu, and Christian Bach.
}

\begin{abstract}
This paper aims to review current research and advancement in technology in organic bioelectronics and to reinvestigate the relationship between organic bioelectronics materials, properties, and application. A comprehensive literature review on organic bioelectronics and its dependent variables created a theoretical foundation for the paper. Using the review-centric theory, a model was developed and presented to encapsulate highly dynamic interaction of organic bioelectronics, synthetic and natural material sources that can be employed in present innovations and its implications on modern technologies. The model highlights the relationship between organic bioelectronics and its four main drivers namely, synthetic material (Piezoelectric energy harvesters), natural materials (electric organs), application (bio-devices, sensors, nanogenerators) and properties. Limitations to this research include; availability of raw materials in appropriate amounts, problems associated with interfacing natural with synthetic materials, maintenance of bioelectronics devices in living organisms and design methods for a variety of specific devices. The empirical data is limited to 4 dependent variables which do not present a conclusive theory about organic bioelectronics. In this review, we explored the possibility of interfacing synthetic material (PVDF) and natural material (electric organ of Electrophorus electricus) by reviewing their properties, fabrication methods to create a composite that has application in a variety of bioelectronics devices.
\end{abstract}

Index Terms-Biosensors; Electrophorus Electricus; Organic Bioelectronics; Piezoelectricity.

\section{INTRODUCTION}

There is a growing literature on network theory in bioelectronics that analyses the interconnection of components associated with organic bioelectronics [1]-[7]. Bioelectronics dates to the 18th century from the work of Luigi Galvani [8]. A variety of bioelectronics devices are being developed today, that advances healthcare, reduces environmental degradation, and promotes scientific progress. The field of bioelectronics is restricted by the lack of materials capable of converting signals between the biotic/abiotic interface.

The past decades have witnessed the exponential growth in the field of organic electronics brought about by the continuous research and development of organic light emitting diodes for use in display applications [9]. Next, organic film transistors were developed for flexible electronics [10] and sensors [11]. Solar energy harvesting devices were also developed using organic photovoltaics [12]. Organic electronic materials have been shown to be

Published on January 27, 2019.

Authors are with University of Bridgeport, USA unique in their ability to interface with biology. However, one need is the development of organic electronic materials that can be easily biofunctionalized [13].

Frontier research in nanomedicine, robotics and in brain/machine interfaces has been successful in explaining the relationship between technology and nature, yet the basic constituents of biology seem to be complex with little similarities to those employed in electronic devices. A conference in 2014 on the topic "Bioelectronics-materials, processes, and applications" organized by the Materials Research Society promoted the congregation of physicists, chemists, biochemists, biologists, and engineers from different field, where they brainstormed on this many-sided challenge, and proposed novel approaches utilizing biocompatible materials for bridging the gap between biological and electrical signals [14].

As stated earlier, there is a limitation of research pertaining the interfacing of biological materials with electronics due to a variety of reasons such as difficulty in achieving the proper amount of material that will elicit physiological interaction with the biological system, achieve a device whose function can be switched on and off in response to biological signaling [15]. Hence, this paper seeks to address a part of this challenge by proposing the possibility of interfacing of a synthetic piezoelectric polymer with Electrophorus electricus cell membrane for application in bioelectronics devices.

\section{RESEARCH METHOD}

Using the review centric research approach, in which the researcher reviews "existing theory and research" [16] and "develop new theoretical insights", a model was developed on the concept of organic bioelectronics and its relation to its independent variables. In this research presented here, the aim is put together the most important "previously established studies and concepts" that has been established in the literature review upon which I provide a synthesis that advances our understanding [16]. In this study, the dependent factors that either promote or regress development of organic bioelectronics were identified. This research approach integrates the "interpretative paradigm" in which a rich description of each factor in the bioelectronics concept and context is established [17].

A comprehensive literature review on organic bioelectronics and its dependent variables created a theoretical foundation for the paper. Using the reviewcentric theory, a model was developed and presented to encapsulate highly dynamic interaction of organic 
bioelectronics, synthetic and natural material sources that can be employed in present innovations and its implications on modern technologies.

The research methods used in this study follows the principles outlined by [16]. It is a comprehensive literature review of organic bioelectronics. Over one hundred articles have been reviewed in relevant journals such as Nature, Cell, Science, others which created a theoretical foundation for the paper. Four case studies for the interfacing of biological materials with electronics have been identified as state-of-the-art [18]-[20]. The contribution of the study is intended to review and summarize the theoretical and empirical knowledge that should inspire new discussions and directions for further research activity.

\section{ORGANIC BIOELECTRONICS: MATERIAL SOURCES, PROPERTIES AND DEVICES}

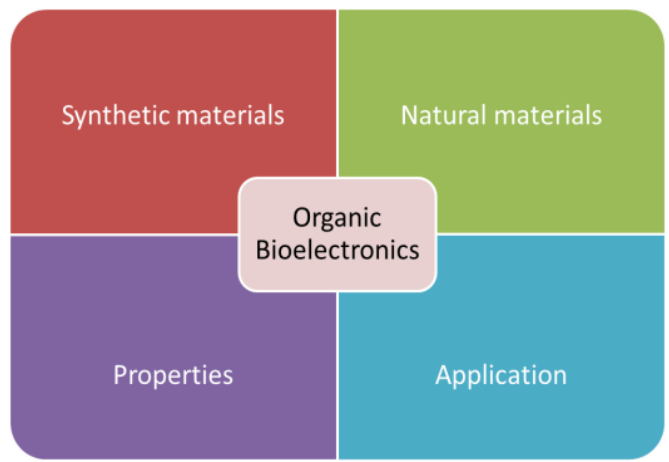

Fig. 1. Organic bioelectronics and its dependent factors

\section{ORGANIC BIOELECTRONICS}

I agree with the fact that organic bioelectronics is a growing field that cuts across academic and industrial interest and seeks to bridge the gap between electronics and biology by using materials such as polymers, organic compounds [21] or conversely can be referred to as a field that incorporate biological materials with electronic devices to improve the wellbeing of living organism [22]. Although the field of "organic bioelectronics" was coined in 2007 with a focus on developing interface communication and regulating cellular function [23], the concept of integrating electric signals with biological systems started in the 1780s, when Luiz Galvani induced muscular activity in the detached leg of a dead frog, a process which pioneered the use of bioelectric forces to study living things [24]. The field of organic cuts across different engineering and life science fields and research is being done continuously to improve on the interface between both fields, hence the field grows at a fast pace [8]. Scientists such as [25] have proven that the field of bioelectronics transcends very minute biomolecules such as DNA but can also be applied in complex organs such as the brain and hence knowledge of this field must be pursued.
TABLE I: ADDITIONAL DEPENDENT VARIABLES DependentVariable Quote and Reference

"Organic bioelectronics comprises the development and studies of organic electronic devices that operate as translators between the signals and functions of biology and those of human-made electronic processing [26],[27] $\mathrm{p}$. 13009."

"Low-temperature processing allows the fabrication of devices with novel form factors, such as transistors integrated on woven fibers [28] p. 357."

"Polyvinyl alcohol (PVA) is another example of a synthetic polymer that has biocompatible properties and has been recently employed as a substrate for the fabrication of biodegradable and biocompatible electronics [29], [30] p. 626."

\section{Synthetic MATERIAl (ENERGY HARVESTING PIEZOELECTRICS)}

Intensive studies are being carried out on the development of lower power wireless sensor networks using energy harvesting devices for maximizing harvested power output [31], hence piezoelectric polymers such as PVDF is being employed for its ability to generate electricity under large reversible deformation [32]. To improve the output capability of energy harvesters, the properties of piezoelectric materials is an influential factor, but the potential of the material is less likely to be fully exploited without an optimized configuration [33]. I agree that although piezoelectric properties are one of the most important features, these materials should also be biocompatible and environmentally friendly [34], therefore piezoelectric sensors are widely used for transforming mechanical vibrations into electrical signals [35]. From research, it has been proven that these properties could be optimized to improve performance [36].

\section{A. Piezoelectric Ceramic (PZT)}

We have previously developed a novel piezoelectric biosensor using lead zirconium titanate (PZT) ceramic resonator as the transducer for label-free, cost-effective, and direct detection of cancer biomarkers [37].

\section{B. Piezoelectric ZnO Nanowires}

Through proper doping, $\mathrm{ZnO}$ can be made transparent and conductive, piezoelectric, or ferromagnetic [38].

\section{Piezoelectric Quartz}

For decades, piezoelectric quartz systems have been used in analytical chemistry because of their oscillating frequency value, which can vary across the megahertz [(MHz), 106 cycles/sec] range, is sensitive and directly proportional to the crystal mass [39].

\section{Polyvinylidene Difluoride (PVDF)}

Polyvinylidene fluoride (PVDF) piezoelectric polymer are more environmentally friendly, compatible and flexible than piezoceramics, and these properties make it possible to assume a full piezoelectric scaffolding without showing any substrate layers [33]. 


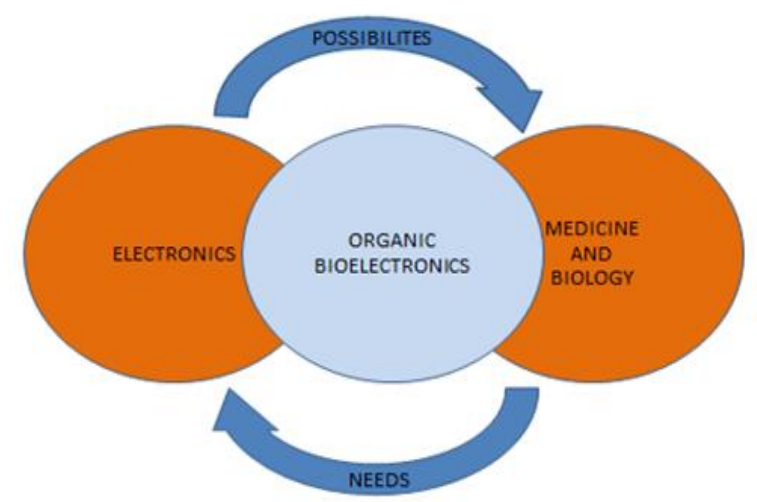

Fig. 2. The interdisciplinary nature of the organic bioelectronics research field.

\section{NATURAL MATERIALS (ELECTRIC ORGAN OF ELECTROPHORUS ELECTRICUS)}

The freshwater electric eel also known as Electrophorus electricus has been researched as the highest producer of electricity in the animal kingdom [40]; it possesses three electric organs namely: main organ, Hunter and Sachs organs with the main organ responsible for the generation of powerful high combined voltage discharges up to $700 \mathrm{~V}$ [41], serving as a weapon against predators and prey [42]. The uniqueness of the cells of electric eels makes it a specialized for study for membrane excitability, electrophysiology, and biochemistry [18]. It has been established that these electric organs are composed of numerous electric cells called electrocytes that are connected in series and in parallel and each of the cells are involved in the production of bouts of electrical discharges [43].

\section{A. Nucleic Acids}

Nucleic acids biopolymers are good candidate molecules for bioelectronics because of their sequence flexibility, which guarantees infinite computational capacity [44].

\section{B. Biomolecular DNA from Salmon Milt}

Biomolecular DNA, as a marine waste product from salmon processing, has been exploited as a biodegradable polymeric material for photonics and electronics [20]

\section{Silk Fibroin}

Silk fibroin is a natural polymer. Its properties such as transparency, biocompatibility, and biodegradability make it appropriate for use as platforms to create an array of photonic devices and transistors. Silk fibroin-based nanogenerators lifetime is controllable and can be used for powering implantable devices [45].

\section{Collagen}

Piezoelectricity is a functional property of collagen, and thus collagen will generate charge under strain (direct piezoelectric effect), and, conversely, undergo deformation in an applied electric field. Previous studies have demonstrated the potential of collagenous scaffolds and hydrogels for tissue engineering applications [46].

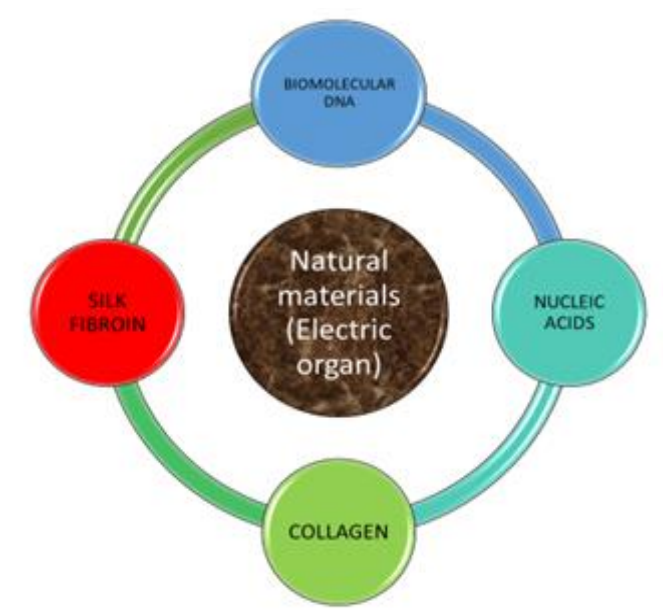

Fig. 3. Natural materials involved in organic bioelectronics.

\section{APPliCATION: (PIEZOELECTRIC NANOGENERATORS)}

Poly (vinylidene fluoride) (PVDF) and its copolymers are the most extensively studied polymers for piezoelectric generators [47], this is because of its flexibility and high piezoelectric property [48], it also has a high piezoelectric response i.e. ability to generate a high electrical discharge under large mechanical deformation [49]. Nanogenerators finds application for energy harvesting devices and selfpowered mechanical systems [50] and is also a promising technology that relies on the coupling effect of piezoelectric materials [51]. I agree therefore that more extensive studies on the optimization and production of nanogenerators should be adequately pursued to ensure higher performance [52].

\section{A. Biosensor}

Biosensors are defined as analytical devices incorporating biological or biological-derived sensing elements either integrated within or intimately associated with physicochemical transducers for analyte detections [53][55]. Biosensors serve as one of the main application of organic bioelectronics. Electrical sensors are emerging as an attractive alternative strategy for biosensor development due to their exceptionally high sensitivity, sometimes down to a femtomolar concentration of analytes [56].

\section{B. Transistor}

Organic transistors can generate an electric field for triggering action potentials in cultured neurons, allowing for the exchange of information between the biological and artificial systems [57].

\section{Organic Photovoltaics}

Organic Photovoltaics (OPV) has great indoor photovoltaic performance because ultra-thin organic layer has strong absorption against the UV-visible spectrum that is good spectral matching with indoor lightings [58].

\section{Supercapacitors}

A type of supercapacitors, consisting of an electricaldouble-layer capacitor and electrochemical pseudocapacitance, has been used for a wide variety of energy storage purposes in the past. However, the supercapacitors that are utilized nowadays consist of graphene and other related $2 \mathrm{D}$ materials that shows great promises in biosensing 
applications [59].

\section{PROPERTIES}

The interest in organic electronics has increased in recent times, brought about by the ease of processing organic materials and the unique properties they possess [60], but I am concerned by some limitations such as; amount and availability of raw materials, tailoring ability, and long-term maintenance of the desired properties of the biomaterial [61]. Switchable bioelectronics has the capabilities of altering their macroscopic properties on demand and can be used for the realization of highly engineered bio-interfaces [62]. Polymers can undergo chemical modification and alter properties of materials upon receipt of stimulus [63], but the degree of stimulus that must be crossed before sensing can occur must be critically lowered. I agree with that the statement that the desirability of organic materials for use in bioelectronic devices is dependent on their exhibition of some exceptional, unique and distinctive electronic, optical and physical properties [64], hence there is a need to tailor these properties to suit the desired output [65].

\section{A. Electrical}

Instability and poor reproducibility of electrical properties of biopolymer-based LB films and time degradation of them represent the most serious problems which still need to be overcome for practical applications of these films in the field of molecular electronics [66].

\section{B. Mechanical}

The outstanding properties of graphene and related 2D materials such as mechanical, electrical, thermal, optical, and long electron mean free paths confers on them the ability to be used for various biosensing applications [59].

\section{Biocompatibility}

"Organic bioelectronics", is an exciting inter-disciplinary field where biocompatible material is interfaced with living tissue and implemented in various electronic devices [67].

\section{Ease of Functionalization}

The development organic bioelectronic devices is a function of the unique properties of organic materials such as; (1) soft mechanical properties which bears close similarities to structures found in biological organisms; (2) a blend of electronic/ionic conductivity that promotes effective signal transport; (3) transparency and versatility; (4) ease of functionalization by proteins and biomolecules to tailor biological properties; and (5) inexpensive production on choice scales [68].

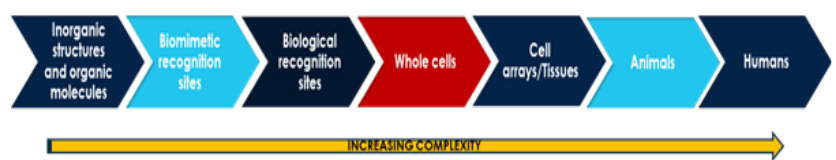

Fig. 4. Hierarchies in the molecular complexity of components for sensor systems:
TABLE II: ADDITIONAL FACTORS THAT ARE CONSIDERED FOR ORGANIC BIOELECTRONICS

\begin{tabular}{|c|c|c|}
\hline & Independent Variables & Quote and References \\
\hline & \multicolumn{2}{|l|}{ PROPERTIES } \\
\hline 1 & $\begin{array}{l}\text { TUNABLE } \\
\text { BIODEGRADABILITY }\end{array}$ & $\begin{array}{l}\text { "It is important to design and fabricate } \\
\text { materials with tunable degradation, } \\
\text { which can undergo quick and } \\
\text { complete degradation when triggered } \\
\text { [69] p. 4135." }\end{array}$ \\
\hline 2 & BIOCOMPATIBILITY & $\begin{array}{l}\text { "Polyvinyl alcohol (PVA) is a } \\
\text { synthetic polymer that has recently } \\
\text { been employed as a substrate for the } \\
\text { fabrication of biodegradable and } \\
\text { biocompatible electronics [70] p. } \\
\text { 651." }\end{array}$ \\
\hline & \multicolumn{2}{|l|}{ NATURAL MATERIALS } \\
\hline 1 & SILK & $\begin{array}{l}\text { "Silk is a natural protein fiber and due } \\
\text { to its biocompatibility and controlled } \\
\text { biodegradability, it was employed as a } \\
\text { platform for the fabrication of } \\
\text { electronics for food sensing } \\
\text { applications, [71] p. } 596\end{array}$ \\
\hline 2 & SHELLAC & $\begin{array}{l}\text { "Shellac is a versatile natural material } \\
\text { which is used as a bio-adhesive } \\
\text { polymer owing to its smooth surface } \\
\text { and excellent film-forming properties, } \\
\text { shellac, and hard gelatin were recently } \\
\text { reported as suitable substrates for } \\
\text { high-performance } \\
\text { featuring all-natural layers [72] p. } \\
\text { 1473." }\end{array}$ \\
\hline & \multicolumn{2}{|l|}{ CHALLENGES } \\
\hline 1 & $\begin{array}{l}\text { LONG-TERM } \\
\text { STABILITY }\end{array}$ & $\begin{array}{l}\text { "However, challenges faces } \\
\text { conducting polymers include poor } \\
\text { electroactive stability and mechanical } \\
\text { properties as well as control of the } \\
\text { mobility, concentration, and } \\
\text { presentation of bioactive molecules } \\
\text { [73] p. 3393." }\end{array}$ \\
\hline 2 & $\begin{array}{l}\text { FABRICATION } \\
\text { METHODS }\end{array}$ & $\begin{array}{l}\text { "A significant challenge lies in the } \\
\text { fabrication of circuits for integrating } \\
\text { sensors with multiplex miniaturized } \\
\text { arrays, as well as the integration of } \\
\text { circuits that will potentially power, } \\
\text { record and transmit the recordings } \\
\text { [74] p.4." }\end{array}$ \\
\hline
\end{tabular}

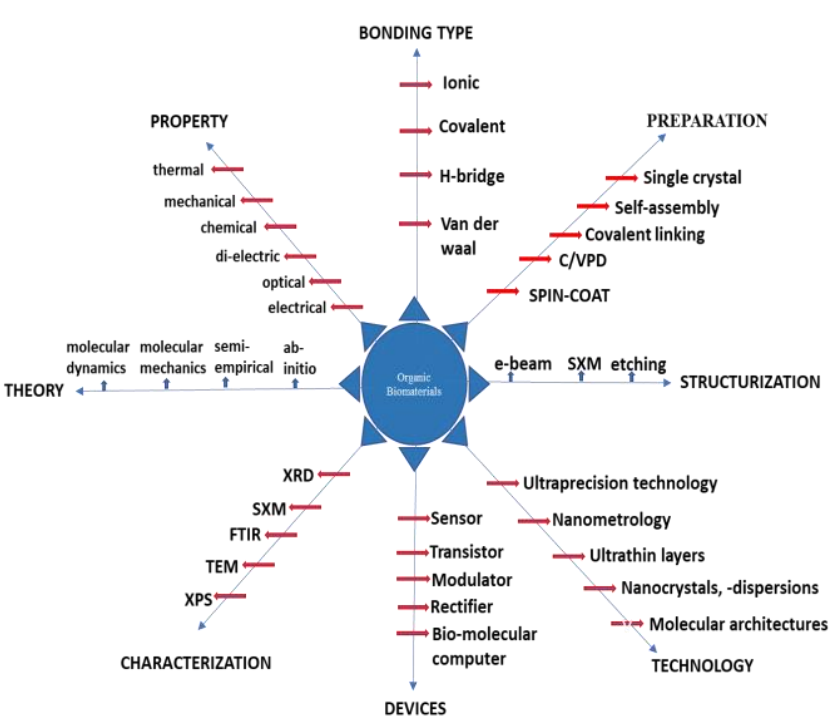

Fig. 5. Different aspects of treating structures based on (bio)molecular materials. Different abbreviations describe just a few characterization techniques: SXM (scanning probe microscopy), TEM (transmission electron microscopy), XRD (X-ray diffraction, (X-ray photoemission spectroscopy), UPS (ultraviolet photoemission spectroscopy), FTIR (Fourier transform infrared spectroscopy), XPS (X-ray photoemission spectroscopy). 


\section{RESUlTS AND DISCUSSION}

Organic electronics is regarded as an interdisciplinary research field where elements of materials science, electronics, physics, and biology merge. The scientific community has contributed towards the development of novel conductive materials (electrodes) that integrates biological matter to electronics to (i) identify events (i.e. biosensing, bio-recognition) or (ii) tailor events to the desired output (i.e. tissue engineering) [75].

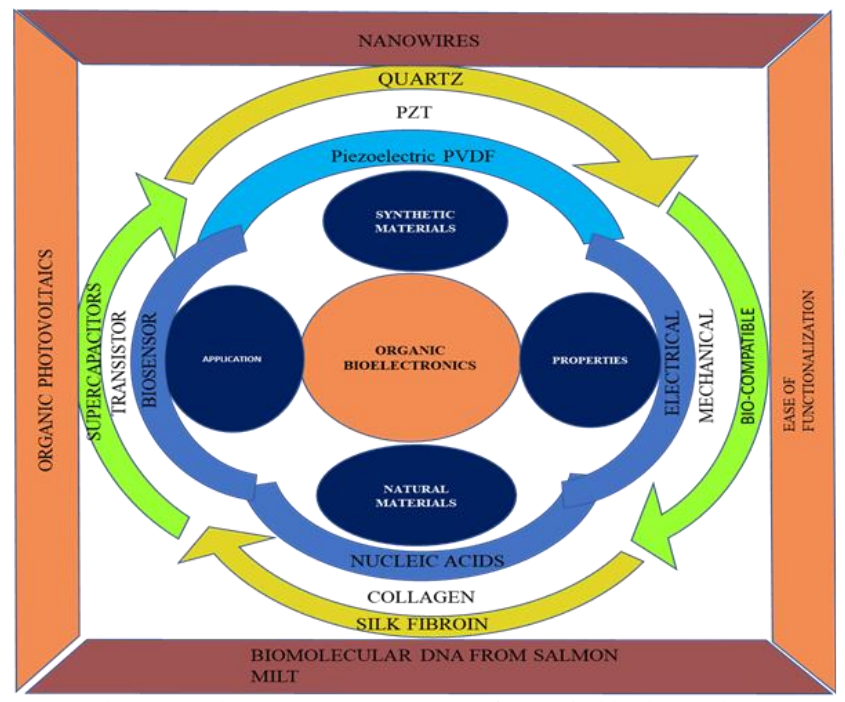

Fig. 6. The inter-dependent nature of organic bioelectronics.

\section{CONTRIBUtion AND NeW Insight}

This review proposes a novel insight for power generation by interfacing energy-harvesting piezoelectric with natural electric eel cells. This is done by understanding the basics of organic bioelectronics which includes properties, fabrication techniques, alternative sources of materials for bioelectronic application. I believe that there is certainly plenty of work to be done in this new field to ensure progress both in understanding key fundamentals issues and in promoting the development of applications. There is a vast array of readily available organic materials that are solely employed in the manufacture of specific bioelectronic devices. Some of these materials are mostly used for a narrow range of applications, but their functionality can be explored and applied to the fabrication of other bioelectronic devices including batteries and fuel cells.

Up until now, organic bioelectronics devices are mostly used for sensing, recording and regulation applications that interface biological systems in vivo and in vitro in the form of planar surfaces. However, the architectural alignment of tissues is neither planar nor static. In contrast, tissues contain variation in the degrees of natural movement as part of their physiological functions. Therefore, the flexibility of organic electronic devices must be considered and improved to increase its biocompatibility and biostability.

\section{CONCLUSION}

The work highlighted here represents just a tiny piece of the enormity of research and development done in the field of organic bioelectronics. It describes the interdisciplinary efforts, aiming to develop novel communication interfaces between electronic components and biological systems Although great progress has been made, there are still certain sustainable challenges in designs and applications of bioelectronics. further development of material properties, the design of devices is necessary will aid in making organic bioelectronics devices useful for several applications.

\section{REFERENCES}

[1] Achrol, R.S. Evolution of the Marketing Organization: New Forms for Turbulent Environments. Journal of Marketing, 1991. 55(4): pp. 77-93.

[2] Achrol, R.S., T. Reve, and L.W. Stern. The Environment of Marketing Channel Dyads: A Framework for Comparative Analysis. Journal of Marketing. 1983. 47(4): pp. 55-67.

[3] C. Anderson, J., H. Håkansson, and J. Johanson. Dyadic Business Relationships Within a Business Network Context. The Journal of Marketing, Vol. 58. 1994. 1-15.

[4] Gadde, L.-E. and L.-G. Mattsson, Stability and change in network relationships. International Journal of Research in Marketing, 1987. 4(1): pp. 29-41.

[5] Iacobucci, D. and N. Hopkins, Modeling dyadic interactions and networks in marketing. Journal of Marketing Research, 1992: pp. 517.

[6] Snehota, I. and H. Hakansson. Developing relationships in business networks. 1995: Routledge London.

[7] Webster, J.D., Water solubility and chlorine partitioning in Cl-rich granitic systems: effects of melt composition at $2 \mathrm{kbar}$ and $800 \mathrm{C}$. Geochimica et Cosmochimica Acta, 1992. 56(2): pp. 679-687.

[8] Malliaras, G.G. Organic bioelectronics: A new era for organic electronics. Biochimica et Biophysica Acta (BBA) - General Subjects, 2013. 1830(9): pp. 4286-4287.

[9] Arias, A.C., MacKenzie, J. D., McCulloch, I., Rivnay, J., \& Salleo, A "Materials and applications for large area electronics: solution-based approaches." Chem Rev, 2010. 110(1): pp. 3-24.

[10] Gelinck, G., Heremans, P., Nomoto, K. and Anthopoulos, T.D., "Organic transistors in optical displays and microelectronic applications". Adv Mater, 2010. 22(34): pp. 3778-98.

[11] Huang, W., Kalpana Besar, Rachel LeCover, Ana María Rule, Patrick N. Breysse, and Howard E. Katz. Highly sensitive NH3 detection based on organic field-effect transistors with tris (pentafluorophenyl) borane as receptor. Journal of the American Chemical Society, 2012 134(36): pp. 14650-14653.

[12] Kippelen, B. and J.-L. Bredas. Organic photovoltaics. Energy \& Environmental Science, 2009. 2(3): pp. 251-261.

[13] Owens, R., Kjall, P., Richter-Dahlfors, A. and Cicoira, F. Organic Bioelectronics-Novel applications in biomedicine. Biochimica et Biophysica Acta (BBA) - General Subjects, 2013. 1830(9): pp. 4283 4285.

[14] Lanzani, G. Materials for bioelectronics: Organic electronics meets biology. Nature Materials, 2014. 13(8): pp. 775-776.

[15] Svennersten, K., Larsson, K.C., Berggren, M. and Richter-Dahlfors, A. Organic bioelectronics in nanomedicine. Biochimica et Biophysica Acta (BBA)-General Subjects, 2011. 1810(3): pp. 276-285.

[16] LePine, J.A. and A. Wilcox-King. Developing novel theoretical insight from reviews of existing theory and research. Academy of Management Review, 2010. 35(4): pp. 506-509.

[17] Dyer, G.W.J. and A.L. Wilkins, Better stories, not better constructs, to generate better theory: A rejoinder to Eisenhardt. Academy of Management Review, 1991. 16(3): pp. 613-619.

[18] Gotter, A.L., M.A. Kaetzel, and J.R. Dedman. Electrophorus electricus as a Model System for the Study of Membrane Excitability. Comparative Biochemistry and Physiology Part A: Molecular \& Integrative Physiology, 1998. 119(1): pp. 225-241.

[19] Nambiar, S. and J.T. Yeow. Conductive polymer-based sensors for biomedical applications. Biosensors and Bioelectronics, 2011. 26(5) pp. $1825-1832$

[20] Singh, T.B., N.S. Sariciftci, and J.G. Grote, Bio-Organic Optoelectronic Devices Using DNA. In Organic Electronics, Springer Berlin Heidelberg, 2009. pp. 73-112.

[21] Löffler, S., B. Libberton, and A. Richter-Dahlfors, Organic Bioelectronic Tools for Biomedical Applications. Electronics, 2015. 4(4).

[22] Kang, P., M.C. Wang, and S. Nam, Bioelectronics with twodimensional materials. Microelectronic Engineering, 2016. 161(Supplement C): pp. 18-35. 
[23] Larsson, K.C., P. Kjäll, and A. Richter-Dahlfors, Organic bioelectronics for electronic-to-chemical translation in modulation of neuronal signaling and machine-to-brain interfacing. Biochimica et Biophysica Acta (BBA) - General Subjects, 2013. 1830(9): pp. 43344344.

[24] Berggren, M. and A. Richter-Dahlfors, Organic Bioelectronics Advanced Materials, 2007. 19(20): pp. 3201-3213.

[25] Rivnay, J., R.M. Owens, and G.G. Malliaras. The Rise of Organic Bioelectronics. Chemistry of Materials, 2014. 26(1): pp. 679-685.

[26] Conrad, M. On design principles for a molecular computer. Communications of the ACM, 1985, 28(5), pp.464-480.

[27] Simon, D.T., Gabrielsson, E.O., Tybrandt, K. and Berggren, M. Organic Bioelectronics: Bridging the Signaling Gap between Biology and Technology. Chemical Reviews, 2016. 116(21): pp. 13009-13041.

[28] Hamedi, M., O. Inganäs, and R. Forchheimer. Towards woven logic from organic electronic fibres. Nature Materials, 2007. 6(5): pp. 357.

[29] Kim, D.H., Lu, N., Ma, R., Kim, Y.S., Kim, R.H., Wang, S., Wu, J., Won, S.M., Tao, H., Islam, A. and Yu, K.J. Epidermal electronics. science, 2011. 333(6044): pp. 838-843.

[30] Martin, D.C., Organic electronics: Polymers manipulate cells. Nature Materials, 2007. 6(9): pp. 626-627.

[31] Li, S., Crovetto, A., Peng, Z., Zhang, A., Hansen, O., Wang, M., Li, $X$. and Wang, F. Bi-resonant structure with piezoelectric PVDF films for energy harvesting from random vibration sources at low frequency. Sensors and Actuators A: Physical, 2016. 247(Supplement C): pp. 547-554.

[32] Melilli, G., Lairez, D., Gorse, D., Garcia-Caurel, E., Peinado, A., Cavani, O., Boizot, B. and Clochard, M.C. Conservation of the piezoelectric response of PVDF films under irradiation. Radiation Physics and Chemistry, 2018. 142(2): pp.54-59.

[33] Song, J., Zhao, G., Li, B. and Wang, J. Design optimization of PVDFbased piezoelectric energy harvesters. Heliyon, 2017. 3(9): pp e00377.

[34] Ko, E.J., Lee, E.J., Choi, M.H., Sung, T.H. and Moon, D.K. PVDF based flexible piezoelectric nanogenerators using conjugated polymer: PCBM blend systems. Sensors and Actuators A: Physical, 2017. 259(Supplement C): pp. 112-120.

[35] Mhetre, M.R. and H.K. Abhyankar, Human exhaled air energy harvesting with specific reference to PVDF film. Engineering Science and Technology, an International Journal, 2017. 20(1): pp. 332-339.

[36] Yang, Z., A. Erturk, and J. Zu, On the efficiency of piezoelectric energy harvesters. Extreme Mechanics Letters, 2017. 15(Supplement C): pp. 26-37.

[37] Nambiar, S. and J.T.W. Yeow, Conductive polymer-based sensors for biomedical applications. Biosensors and Bioelectronics, 2011. 26(5): pp. $1825-1832$

[38] Chen, Y., et al., Multifunctional ZnO-Based Thin-Film Bulk Acoustic Resonator for Biosensors. Journal of Electronic Materials, 2009. 38(8): pp. 1605-1611.

[39] Skládal, P., Piezoelectric biosensors. TrAC Trends in Analytica Chemistry, 2016. 79(Supplement C): pp. 127-133.

[40] Cordeiro, M.C.R., et al., Microheterogeneity of desmin in the electric organ and dorsal muscle of the electric eel Electrophorus electricus. Comparative Biochemistry and Physiology Part A: Physiology, 1995. 111(3): pp. 345-350

[41] Jie, Y., et al., A structural bionic design: From electric organs to systematic triboelectric generators. Nano Energy, 2016 27(Supplement C): pp. 554-560.

[42] Souza, M.L.S., et al., Identification and distribution of chondroitin sulfate in the three electric organs of the electric eel, Electrophorus electricus (L.). Comparative Biochemistry and Physiology Part B Biochemistry and Molecular Biology, 2007. 146(2): pp. 227-233.

[43] Catania, Kenneth C., Electric Eels Concentrate Their Electric Field to Induce Involuntary Fatigue in Struggling Prey. Current Biology, 2015. 25(22): pp. 2889-2898.

[44] Chen, Q., et al., Control of electrochemical signals from quantum dots conjugated to organic materials by using DNA structure in an analog logic gate. Bioelectrochemistry, 2016. 111(Supplement C): pp. 1-6.

[45] Kim, K.N., et al., Silk fibroin-based biodegradable piezoelectric composite nanogenerators using lead-free ferroelectric nanoparticles. Nano Energy, 2015. 14(Supplement C): pp. 87-94.

[46] Denning, D., et al., Electromechanical properties of dried tendon and isoelectrically focused collagen hydrogels. Acta Biomaterialia, 2012 8(8): pp. 3073-3079.

[47] Abolhasani, M.M., K. Shirvanimoghaddam, and M. Naebe, PVDF/graphene composite nanofibers with enhanced piezoelectric performance for development of robust nanogenerators. Composites Science and Technology, 2017. 138(Supplement C): pp. 49-56.

[48] Singh, H.H., S. Singh, and N. Khare, Design of flexible $\mathrm{PVDF} / \mathrm{NaNbO}$ /RGO nanogenerator and understanding the role of nanofillers in the output voltage signal. Composites Science and Technology, 2017. 149(Supplement C): pp. 127-133.

[49] Pi, Z., et al., Flexible piezoelectric nanogenerator made of poly(vinylidenefluoride-co-trifluoroethylene) (PVDF-TrFE) thin film Nano Energy, 2014. 7(Supplement C): pp. 33-41.

[50] Beringer, L.T., et al., An electrospun PVDF-TrFe fiber sensor platform for biological applications. Sensors and Actuators A Physical, 2015. 222(Supplement C): pp. 293-300.

[51] Yu, Y., et al., Biocompatibility and in vivo operation of implantable mesoporous PVDF-based nanogenerators. Nano Energy, 2016 27(Supplement C): pp. 275-281.

[52] Choi, M., et al., Mechanical and electrical characterization of PVDF$\mathrm{ZnO}$ hybrid structure for application to nanogenerator. Nano Energy, 2017. 33(Supplement C): pp. 462-468.

[53] Turner, A.P., Biosensors--sense and sensitivity. Science, 2000. 290(5495): pp. 1315-1317.

[54] Banica, F.-G., Chemical sensors and biosensors: fundamentals and applications. 2012: John Wiley \& Sons.

[55] Turner, A.P., Biosensors: sense and sensibility. Chemical Society Reviews, 2013. 42(8): pp. 3184-3196.

[56] Song, H.S., et al., 3D hydrogel scaffold doped with 2D graphene materials for biosensors and bioelectronics. Biosensors and Bioelectronics, 2017. 89(Part 1): pp. 187-200

[57] Spanu, A., et al. An organic transistor-based system for reference-less electrophysiological monitoring of excitable cells. Scientific Reports 2015. 5, 8807 DOI: 10.1038/srep08807.

[58] Aoki, Y., Photovoltaic performance of Organic Photovoltaics for indoor energy harvester. Organic Electronics, 2017. 48(Supplement C): pp. 194-197.

[59] Zhang, T., et al., Synthesis of graphene and related two-dimensional materials for bioelectronics devices. Biosensors and Bioelectronics, 2017. 89(Part 1): pp. 28-42.

[60] Tarabella, G., et al., New opportunities for organic electronics and bioelectronics: ions in action. Chemical Science, 2013. 4(4): pp. 1395-1409.

[61] Wasilewski, T., J. Gębicki, and W. Kamysz, Bioelectronic nose: Current status and perspectives. Biosensors and Bioelectronics, 2017. 87(Supplement C): pp. 480-494.

[62] Parlak, O. and A.P.F. Turner, Switchable bioelectronics. Biosensors and Bioelectronics, 2016. 76(Supplement C): pp. 251-265.

[63] Oh, E.H., H.S. Song, and T.H. Park, Recent advances in electronic and bioelectronic noses and their biomedical applications. Enzyme and Microbial Technology, 2011. 48(6): pp. 427-437.

[64] Osikoya, A.O. and A. Tiwari, Recent advances in 2D bioelectronics. Biosensors and Bioelectronics, 2017. 89(Part 1): pp. 1-7.

[65] Göpel, W., Bioelectronics and nanotechnologies1Presented at "Biosensors 1996" in Bangkok, Thailand.1. Biosensors and Bioelectronics, 1998. 13(6): pp. 723-728.

[66] Nicolini, C., Supramolecular architecture and molecular bioelectronics. Thin Solid Films, 1996. 284-285(Supplement C): pp. $1-5$.

[67] Irimia-Vladu, M., "Green" electronics: biodegradable and biocompatible materials and devices for sustainable future. Chemical Society Reviews, 2014. 43(2): pp. 588-610.

[68] Malliaras, G. and M.R. Abidian, Organic Bioelectronic Materials and Devices. Advanced Materials, 2015. 27(46): pp. 7492-7492.

[69] Acar, H., et al., Study of Physically Transient Insulating Materials as a Potential Platform for Transient Electronics and Bioelectronics. Advanced Functional Materials, 2014. 24(26): pp. 4135-4143.

[70] Bettinger, C.J. and Z. Bao, Organic thin-film transistors fabricated on resorbable biomaterial substrates. Advanced materials, 2010. 22(5): pp. 651-655.

[71] Tao, H., et al., Silk-Based Conformal, Adhesive, Edible Food Sensors. Advanced Materials, 2012. 24(8): pp. 1067-1072.

[72] Irimia-Vladu, M., et al., Natural resin shellac as a substrate and a dielectric layer for organic field-effect transistors. Green Chemistry, 2013. 15(6): pp. 1473-1476

[73] Green, R.A., et al., Conducting polymers for neural interfaces: Challenges in developing an effective long-term implant. Biomaterials, 2008. 29(24): pp. 3393-3399.

[74] Strakosas, X., M. Bongo, and R.M. Owens, The organic electrochemical transistor for biological applications. Journal of Applied Polymer Science, 2015. 132(15): pp. 1-14

[75] Owens, R.M. and G.G. Malliaras, Organic electronics at the interface with biology. MRS bulletin, 2010. 35(6): pp. 449-456. 


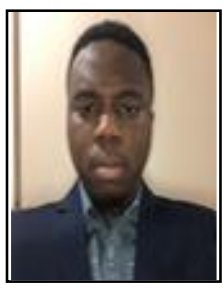

Godspower W. Omokhunu received his B.Sc. in Biochemistry in 2013 at the University of Benin, Benin, Nigeria and is currently a graduate student pursuing a master degree in biomedical engineering in the University of Bridgeport, Connecticut, USA. $\mathrm{He}$ is currently a joint researcher in Prof. Christian Bach laboratory at the University of Bridgeport, studying cell signaling and cell surface interaction with organic materials.

$\mathrm{He}$ is currently a member of National Society of Black Engineering (NSBE), Bridgeport Chapter. He is also a prospective $\mathrm{Ph}$.D. student for a number of universities where he would continue his research in material science. 